\title{
Libraries, Archives, and Museums in the Twenty-First Century: Intersecting Missions, Converging Futures?
}

LIBRARIES, ARCHIVES, AND MUSEUMS are places where we learn about ourselves, the world around us, and what came before us. They inspire us to make a better future by helping us remember and understand the past. As cultural heritage institutions, libraries, archives, and museums share common goals to acquire, preserve, and make accessible artifacts and evidences of the world's social, intellectual, artistic, even spiritual achievements. Yet to what extent do common goals imply common means? What benefits might be realized by bringing professionals from these allied fields into closer communication?

Asking these and related questions was the purpose of "Libraries, Archives, and Museums in the Twenty-First Century: Intersecting Missions, Converging Futures?" the 47th annual preconference of the Rare Books and Manuscripts Section of the Association of College and Research Libraries. Held June 20-23, 2006, in Austin, Texas, the conference attracted 364 participants, making it the largest preconference in RBMS history. Evidently, the questions we addressed are meaningful to many.

The conference theme was suggested in part by our venue. Our host, the Harry Ransom Center at the University of Texas at Austin, had recently completed extensive building renovations. Large museum-like exhibitions spaces were created on the ground floor and a spacious new library reading room and seminar facilities were added on the level above. The transformation provided a laboratory in situ for conference participants to reflect on the merger of library, archives, and museum functions in a single setting.

The theme was also stimulated by other conferences and conversations. More than others perhaps, rare book and manuscript librarians are aware of how their roles straddle institutional and professional identities: on the one hand, we manage collections of texts; on the other, artifacts. As early as 1988, an RBMS preconference 
had contemplated the future of special collections libraries as "museums of the book," a point of reflection that has only sharpened in the light of transformations that general library collections are undergoing in the dawning digital age.

In 2003, a long-standing formal liaison relationship between the American Library Association and the Society of American Archivists was expanded to include the American Association of Museums. Sessions of the ALA/SAA/AAM Joint Committee on Libraries and Archives and Museums (CALM), which includes co-chairs and member representatives from each of the organizations, now convene three times a year at their respective professional meetings to discuss issues of mutual concern and share information about programs. ${ }^{2}$

"21st Century Curatorship" was an invitational meeting of library, museum, and informational professionals held at the New York Public Library July 22-23, 2004. ${ }^{3}$ Organized jointly by NYPL and the British Museum with the sponsorship of the Andrew W. Mellon Foundation, the conference sought to define the changing roles of curators in research libraries and museums and to determine what knowledge, experience, and skills are required to fulfill these roles. The second biennial "Choices and Challenges" National Symposium conference, held October 8-10, 2004, at the Benson Ford Research Center in Dearborn, Michigan, brought together nationally prominent speakers with curators and archivists from history museums, historical societies, and collections. In July 2005, RLG conducted a forum for its members entitled "Libraries, Archives, \& Museums-Three-Ring Circus, One Big Show?" 4 Fom this perspective, the 2006 RBMS preconference simply marked another round in an ongoing conversation.

Yet an element of chance intersection gave our symposium a special twist. Shortly after accepting the responsibility of chairing the 2006 Annual RBMS Preconference program planning committee, I headed off to one of our semiannual RBMS meetings. The airline reservation system seated me next to Susan Malbin, a program officer from the Institute of Museum and Library Services (IMLS). By the time we landed, I had begun to see how IMLS could help us expand the upcoming RBMS program to incorporate a greater diversity of viewpoints and participants than our usual resources would otherwise allow.

1. "Libraries \& Museums: Leaves from Each Other's Books," the 29th annual RBMS preconference held July 5-8, 1988, in New Orleans, Louisiana.

2. For example, the 2005 AAM annual meeting, "A Defining Moment: Museums and the Crossroads," included a series of Library-Museum Day programming in collaboration with the Institute of Library and Museum Services; see the 2005 AAM annual report at http:/ /www.aam-us.org/aboutaam/ governance/ upload/AAM-FY2005-annual-report.pdf, p. 17.

3. http://www.nypl.org/research/curator/index.html.

4. http://www.rlg.org/en/page.php?Page_ID=20521. 
We submitted a successful grant application to IMLS and were awarded \$93,106 in matching funds to produce our conference. The largest portion of the IMLS grant went to funding attendance scholarships for new and aspiring professionals. We received an astonishing 352 applications for thirty-three places. With such a large pool, selection was naturally difficult. We awarded scholarships to seven applicants who identified their career focus with museums, eleven with archives, and thirteen with libraries. Fourteen scholarship winners came from professionally underrepresented racial and ethnic backgrounds.

Numbering nearly one in ten of the total attendees, the scholarship recipients contributed much to the dynamism of the conference. They participated actively in question and answer periods after the main presentations as well as in the discussion groups we organized around central themes. We asked them to write about their impressions after the conference closed. The following quotations from their essays reveal what they learned and their reactions to the questions raised by the conference.

A current library school student commented:

While I had always taken it for granted that [libraries, archives, and museums] are cultural organizations, I had not really thought about their roles as memory institutions or as catalysts for civic improvement. I certainly had not thought about the differences in the ways [they] provide access to their materials.

Another library school student who has been working at a research library likewise surmised that differing modes of access define libraries, archives, and museums and affect the ways these organizations might work together:

During the conference, I got the impression that libraries, archives, and museums do possess many common concerns, and convergence may be crucial to their relevance and survival. However, this process might be even more difficult and contentious than I had imagined. I realized how important it is to be mindful of values within the disciplines - where they overlap as well as where they differ. The library world places a high value on access and standardization, but these may not be the ideals of all archives and museums. As (or if) we move towards convergence, we should not assume that our missions intersect in all aspects. How might we respectfully collaborate in ways that are meaningful to our institutions and our users?

Meanwhile, several scholarship recipients from museum backgrounds reacted against suggestions that libraries place a higher value on access than museums. For instance, a recipient who works at a historical society commented: 
I was also a bit surprised at some of the attitudes from these [library] professionals toward museum collections and accessibility, mainly that museums don't do enough or don't come across as being "user friendly" like libraries and archives do.

In a similar vein, a library school graduate who sought work as an archivist before landing a position at a museum remarked:

It was interesting to hear the opinions of the librarians-who vastly outnumbered the other types of professionals - and how in general, they seemed to assume that library techniques were the way to go if other types of organizations were interested in any meaningful collaboration. ... [T] The sentiment that libraries are correct, and museums might not have as much to offer, definitely seemed to be a pervasive one. It would be nice if a few RBMS members could make it to an AAM conference, or even just sit down with an information professional from a museum to dispel some myths.

A young museum professional from Sweden pointed out that differences in access were only part of what distinguishes libraries, archives, and museums:

[A]s the conference progressed it became abundantly clear that collection based definitions of libraries, archives, and museums are not valid, have never been valid, and never will be valid. Everyone collects everything. Yet each has a unique method of classifying and working with each thing. No one method is more or less valid than another, and here perhaps is the key to working together: not our similarities in collections, but our differences in how we work with them.

A new library cataloger who has worked with a collection of artists' books at a major metropolitan institution also perceived that greater differences existed among libraries, archives, and museums than she had imagined, and which she thought could narrow opportunities for collaboration:

$[T]$ he conference settled definitely in my mind the questions of its title: intersecting missions? Yes. Converging futures? Probably not... It's clear to me now that the really significant common area of work among the three kinds of institutions is in exhibitions.

Echoing her sentiments and picking up on the topic of exhibitions, a museum studies graduate employed at a national heritage area commented: 
Perhaps the most important part of the title, however, was the question mark at the end. Upon extended reflection, then, I would answer the posed question with a resounding "no."... As one of the few museum professionals at the conference, I was surprised at how little I could relate to the many of the session discussions, possibly because history museums actually have much less in common with libraries and archives than I formerly realized. While quality cataloguing is perhaps the best way archivists or librarians can serve their clientele, museums prioritize creativity in creating engaging exhibits; cataloguing in museums is often a lower priority. Inherent differences in visitor expectations also divide museums from archives and libraries. Archives and library patrons seek specific knowledge or sources, while museum visitors are more passive participants who come with expectations more closely related to entertainment.

Returning to the issue of access, she went on to observe that the online environment perhaps holds the most potential for library, archives, and museum collaboration, or at least similarities in approach:

The most fascinating discussion for me at the conference pertained to access to objects in museums versus access to archival and library collections.... $[\mathrm{T}]$ he difficulties with providing access to object collections are multifold, beginning with the fact that security and safety issues will always make everprotective curators wary of granting public access to collections. However, there are certain compromises that can be made by those in control of museum collections. A prime example of this is the creation of online databases; museums are decades behind archives and libraries in making their collections searchable online. I can proudly say that since I have returned from Austin, I have been working with my institution to put our collections database on our website. This is something that we had discussed doing in the past, but conversations at the conference made me realize that online access should be a priority for museums like my own.

Other scholarship recipients focused on educational expectations and opportunities, a theme that was the subject of a lively panel and discussion group. A recent library and information science school graduate expressed frustration over limitations in her course of study:

When I entered library school two years ago, I was interested in pursuing a career related to all three professions and I believed that what I would learn in library school could somehow be carried into a career in a library, archive, or museum. However, as I progressed through my library studies, 
I noticed that even though the discourse presented among library scholars and professional publications recognized some overlap in the library, archives, and museum fields, they were often nebulous when it came to how these professions could actually work together and be, in a sense, amalgamated into a course of study or an academic program for budding stewards of our cultural heritage.

Picking up on another issue raised by the panel on educational preparation, a library and information science school graduate with certificate in archives and records management who has been working as a project archivist at an ethnic archives suggested that libraries, archives, and museums should recognize and embrace their roles as cultural heritage institutions to create more diverse collections and broader access to professional education:

Even within issues of access already created by differences in policy and approach between libraries, archives and museums, there are additional layers of exclusion which fail to be recognized and articulated. A blind spot will hardly be rectified if the respective professional communities are not attuned to the reproduction of these patterns of exclusion in their own institutions... [Furthermore,] the continued lack of access to the library, archives and museums professions by racial minorities, and the subsequent lack of diversity in the professions have ramifications for the diversity of perspectives to be had within cultural institutions.

The evaluations we received from our nonscholarship attendees echoed and reinforced observations made by our scholarship recipients. To sum up what we learned from three intense days together, we may say that the relationships among libraries, archives, and museums as institutions depend upon the ways they relate to the collections or content they manage as well as upon the ways they relate to their audiences. These relationships imply certain values, and values, in turn, shape practices. Awareness of differences in values and practices can help library, archives, and museum professionals understand one another better and collaborate more effectively over issues and initiatives of mutual concern.

To the extent that libraries, archives, and museums remain vital cultural institutions, fostering continued conversation among them and with the audiences they serve can only be beneficial, regardless of the extent to which their missions may intersect or their futures converge. We hope the edited versions of selected presentations from the 2006 RBMS preconference presented in these pages will be a meaningful contribution to an ongoing dialog. A portion of our IMLS grant will help fund a panel presentation on our conference outcomes at the annual meet- 
ing of the American Association of Museums in May 2007, and we will work with CALM and the Society of American Archivists to disseminate our results more widely. The grant has also enabled us to print hundreds of extra copies of this issue of $R B M$ for distribution in the library, archives, and museum communities. Details regarding the preconference program remain available on the RBMS Web site (http:/ / www.rbms.info) under "conferences." Comments and questions are most welcome.

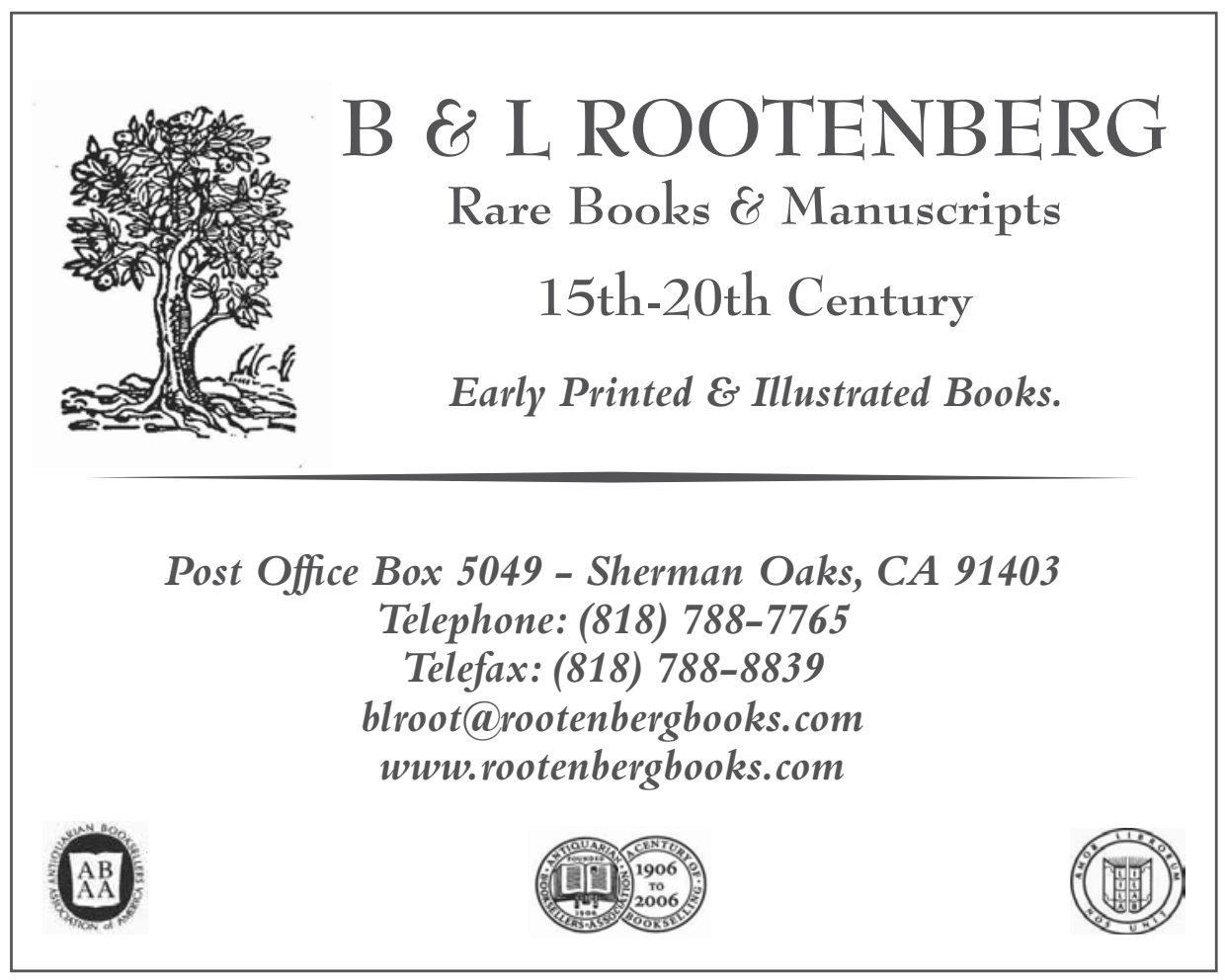

